\title{
Perfis físico-químico e cromatográfico de amostras de própolis produzidas nas microrregiões de Franca (SP) e Passos (MG), Brasil
}

\author{
João P.B. Sousa', Niege A.J.C. Furtado², Raquel Jorge ${ }^{2}$, Ademilson E.E. Soares ${ }^{3}$, \\ Jairo K. Bastos ${ }^{1 *}$
}

${ }^{1}$ Departamento de Ciências Farmacêuticas, Faculdade de Ciências Farmacêuticas de Ribeirão Preto, Universidade de São Paulo, Avenida do Café, s/n, 14040-903, Ribeirão Preto, SP, Brasil,

${ }^{2}$ Núcleo de Pesquisa em Ciências Exatas e Tecnológicas, Universidade de Franca, Avenida Dr. Armando Salles Oliveira 201, 14404-600, Franca, SP, Brasil,

${ }^{3}$ Departamento de Genética, Faculdade de Medicina de Ribeirão Preto, Universidade de São Paulo, Avenida do Café, s/n, 14049-900, Ribeirão Preto, SP, Brasil

\begin{abstract}
RESUMO: Própolis é um termo genérico utilizado para denominar o material resinoso e balsâmico coletado e processado pelas abelhas a partir de várias fontes vegetais. A composição da própolis é complexa e ocorrem variações em função de fatores como a flora da região, estações do ano e características genéticas das abelhas. Sendo assim, objetivou-se neste trabalho realizarem-se análises para o controle de qualidade físico-químico de amostras de própolis, provenientes de seis diferentes locais situados nas microrregiões de Franca (SP) e Passo (MG), bem como verificar a qualidade deste produto para o consumo humano e selecionar regiões produtoras de própolis verde. Os resultados obtidos para as diferentes análises variaram entre as seis diferentes áreas. As localidades de Capetinga-MG e o distrito de Chave da Taquara-SP produziram própolis verde durante todo o período de coleta. Além disso, as amostras de própolis provenientes destes locais mostraram-se satisfatórias para o consumo humano haja vista que os teores de flavonóides totais variaram entre 1 e $2 \% \mathrm{p} / \mathrm{p}$ e os teores de ácidos fenólicos oscilaram entre 4 e $8 \% \mathrm{p} / \mathrm{p}$.
\end{abstract}

Unitermos: Baccharis dracunculifolia, própolis, ácidos fenólicos, análises físico-químicas e cromatográficas, microrregiões de Franca (SP) e Passos (MG).

\begin{abstract}
Physical chemical and chromatographic profiles of propolis samples produced in the micro regions of Franca (SP) and Passos (MG), Brazil". Propolis is a generic term used to denominate the resinous and balsamic material collected from several vegetable sources and processed by the bees. Its chemical composition is complex and depends on the plant species of the region, seasonality, and genetic characteristics of the bees. Therefore, the aim of this work was to establish the physical and chemical quality controls of propolis samples from six different Brazilian micro regions of Franca (SP) and Passos (MG), as well as to verify the propolis quality for human consumption, and to select green propolis producing areas. The obtained results for the different analyses varied among the six different sites. The sites of Capetinga (MG) and Chave da Taquara (SP) produced green propolis during the whole collection period. Besides, the analyses of propolis samples from these sites indicated that they are satisfactory for human consumption based on the total flavonoids content, which varied between 1 and $2 \%(\mathrm{w} / \mathrm{w})$ and on the phenolic acids content, which varied between 4 and $8 \%(\mathrm{w} / \mathrm{w})$.
\end{abstract}

Keywords: Baccharis dracunculifolia, propolis, phenolic acids, chromatography and chemical analyses, micro region of Franca (SP) and Passos (MG).

\section{INTRODUÇÃO}

Própolis é um termo genérico utilizado para denominar o material resinoso e balsâmico coletado e processado pelas abelhas a partir de várias fontes vegetais (Bankova, 2005). A própolis possui composição química complexa, cuja coloração pode variar do amarelo claro, marrom esverdeado ao negro (Marcucci et al., 2001). Várias substâncias presentes na própolis provêm de flores, ramos, brotos, exsudatos e de outras partes do tecido vegetal. Estas substâncias podem ser modificadas na colméia pela adição de secreções salivares (Santos et al., 2003). Estudos realizados mostram que mais de trezentas substâncias foram identificadas em amostras de própolis, com predominância de flavonóides (flavonas, flavonóis, flavanonas), das quais destacam-se: galangina, crisina, tectocrisina, pinocembrina, campferol e quercetina, bem como os aldeídos aromáticos (vanilina e isovanilina), cumarinas, ácidos fenólicos (ácido caféico, ferúlico, cinâmico e cumárico), ácidos orgânicos (ácido benzóico) e alguns oligoelementos, tais como: alumínio, vanádio, 
ferro, cálcio, silício, manganês, estrôncio, e vitaminas B1, B2, B6, e C (Bankova et al., 1998; Bankova et al., 2000; Marcucci et al., 2001).

Por apresentar atividades biológicas, a própolis vem sendo utilizada há milhares de anos pelo homem, para mumificação de cadáveres (Salatino 2005), para tratamento de infecções bacterianas (Sforcin et al., 2000) e fúngicas (Murad et al., 2002), bem como devido às atividades antiinflamatória (Reis et al., 2000), contra afecções do trato respiratório (Tavares et al., 2006; Soares et al., 2006), antioxidante (Simões et al., 2004), imunomodulatória (Sforcin et al., 2005; Missima et al., 2006), antitumoral (Bazo et al., 2002) e antiúlcera (Barros et al., 2006).

A própolis brasileira produzida no cerrado, rica em derivados prenilados do ácido- $p$-cumárico (Bankova; Marcucci, 1999), é conhecida internacionalmente como própolis verde, green propolis, a qual tem como principal fonte vegetal à espécie de Baccharis dracunculifolia D.C., possuindo uma coloração característica que é utilizada pelos japoneses para sua rápida identificação no processo de comercialização (Park et al., 2004). A própolis verde é amplamente consumida no Japão como suplemento alimentar na profilaxia de doenças devido as suas ótimas características organolépticas e também em razão do menor teor de poluentes ambientais.

A própolis possui enorme importância medicinal e econômica, sendo comercializada em várias preparações farmacêuticas e cosméticas, tais como: comprimidos, pastilhas, dentifrícios, loções, cremes faciais, tinturas, pomadas, etc. (Bankova et al., 2000; Park et al., 2002). Tem sido observado um aumento significativo do interesse da população pelo produto, do número de criadores de abelhas que investe na melhoria da produção da própolis e de empresas processadoras deste material (Pereira et al., 2002).

Tendo em vista que a composição da própolis varia em função de fatores como a flora da região, estações do ano e características genéticas das abelhas, objetivouse neste trabalho realizarem-se análises para o controle de qualidade químico de amostras de própolis provenientes de seis diferentes localidades das microrregiões de Franca (SP) e Passos (MG), bem como verificar a qualidade deste produto para o consumo humano e selecionar regiões produtoras de própolis verde.

\section{MATERIAL E MÉTODOS}

\section{Produção e coleta das amostras de própolis}

Inicialmente, visando à produção de própolis, foram instaladas duas colméias equipadas com coletores do tipo Apis-Flora, identificados numericamente, em seis localidades diferentes. As colônias foram formadas por abelhas Apis mellifera scutellata geneticamente selecionadas. Estas colônias apresentavam uma abelha rainha, cerca de 15 zangões e aproximadamente 50 mil abelhas operárias e durante o regime de chuvas foi necessário utilizar alimentação artificial (água/açúcar na proporção 1:1).

As amostras de própolis foram coletadas em média a cada 45 dias, durante 12 meses, durante o período de setembro de 2001 a dezembro de 2002, nas seguintes localidades: Fazenda Experimental da Universidade de Franca (Franca-SP), Fazenda Fernando Cury (Ribeirão Corrente-SP), Fazenda Princesa dos Campos (RestingaSP), Fazenda Tudo Isso e o Céu Também (Rifaina-SP), Fazenda Chave da Taquara (Chave da Taquara-SP) e Fazenda São Marcos (Capetinga-MG). As primeiras cinco localidades pertencem à microrregião de Franca (SP) e a última à microrregião de Passos (MG).

\section{Preparação das tinturas das amostras de própolis}

As tinturas foram obtidas a partir de $20 \mathrm{~g}$ de própolis in natura pulverizada. $\mathrm{O}$ material foi submetido à maceração com $50 \mathrm{~mL}$ de solução hidroalcoólica utilizando-se álcool de cereais $70 \%$ por 15 dias, com agitação ocasional. Após este período, o material foi filtrado e a torta de filtração foi submetida novamente à maceração nas mesmas condições. Ao final de 30 dias obtiveram-se cerca de $90 \mathrm{~mL}$ das tinturas, as quais foram armazenadas em frascos âmbares, mantidas ao abrigo da luz e à temperatura ambiente.

\section{Análises físico-químicas}

As tinturas hidroalcoólicas foram submetidas às análises para determinação da densidade, do teor alcoólico e do teor de sólidos solúveis de cada amostra. Os teores de cinzas, umidade e ceras foram obtidos utilizando-se uma alíquota da própolis in natura pulverizada. Todos os procedimentos foram realizados de acordo com a Farmacopéia Brasileira (1977).

O teor de flavonóides totais nas tinturas obtidas foi determinado por espectrofotometria utilizandose cloreto de alumino $\left(\mathrm{AlCl}_{3}\right)$ como reagente de deslocamento, de acordo com a metodologia descrita por Woisky (1996). Para o estudo de linearidade e obtenção da equação para determinação do teor de flavonóides totais nas tinturas de própolis, soluções do padrão quercetina foram preparadas em diferentes concentrações e a curva analítica foi obtida.

A avaliação da atividade antioxidante das tinturas obtidas foi realizada de acordo com a metodologia descrita na Farmacopéia Brasileira (1977). Utilizou-se permanganato de potássio $\left(\mathrm{KMnO}_{4}\right)$ como agente oxidante. $\mathrm{O}$ tempo de reação foi determinado com o auxílio de um cronômetro.

\section{Determinação por CLAE dos teores dos principais ácidos fenólicos}

As amostras de própolis foram analisadas 
em cromatógrafo da marca Shimadzu composto por três bombas Shimadzu LC-10AD, detector espectrofotométrico por conjunto de arranjo de diodos UV/VIS Shimadzu SPD-M10A $A_{\mathrm{vP}}$, sistema controlador SCL-10A ${ }_{\mathrm{VP}}$, conectado a um computador com software Shimadzu Class-VP versão 5.02, injetor automático $\left(\mathrm{SIL}-10 \mathrm{AD}_{\mathrm{vp}}\right)$ e coletor de frações FRC-10A. Utilizouse coluna cromatográfica analítica de fase reversa CLCODS (M) - Shimadzu, 4,6 mm x $250 \mathrm{~mm}$, diâmetro das partículas $5 \mu \mathrm{m}$ e pré-coluna analítica de fase reversa $\mathrm{C}_{18}$ SGE. Empregou-se sistema de eluição por gradiente, iniciando com a mistura de $0,8 \%$ de ácido acético: 0,3 $\%$ de acetato de amônio: $5 \%$ de metanol em água e 25 $\%$ de acetonitrila em água e terminando com $100 \%$ de acetonitrila em 60 minutes (vazão de $1,0 \mathrm{~mL} / \mathrm{min}$ ). As amostras de própolis foram solubilizadas em metanol na concentração de $1 \mathrm{mg} / \mathrm{mL}$ e uma alíquota de $20 \mu \mathrm{L}$ foi injetada no sistema cromatográfico. Para a determinação do percentual dos ácidos fenólicos foram utilizados os dados de regressão linear obtidos por meio de curvas analíticas, as quais foram elaboradas utilizando-se padrões cromatográficos. Os ácidos caféico e cumárico foram adquiridos da ACROS Organics, New Jersey, USA, e ácido 3-prenil-p-cumárico (drupanina), ácido 3,5-diprenil-p-cumárico (artepelin C) e ácido 3-prenil-4diidrocinamoiloxi-cinâmico (bacarina) foram isolados a partir de amostras de própolis verde (Gregório, 2003; Da Silva Filho, 2006). Os compostos fenólicos das amostras estudadas foram identificados com base na biblioteca de padrões existente no Laboratório de Farmacognosia (FCFRP-USP). Benzofenona (ACROS Organics, New Jerssey, USA) foi utilizada como padrão interno.

\section{RESULTADOS E DISCUSSÃO}

\section{Produção de própolis}

A própolis foi produzida em todos os meses, durante o período de estudo, na localidade de Franca. Entretanto, na microrregião de Passos não ocorreu o depósito de própolis no coletor em outubro de 2001. Nesta fase inicial de coleta, as colônias encontravam-se em fase de adaptação ao clima e à flora disponível na região em estudo. Assim, eventualmente, a produção de própolis pode ser alternada considerando os três meses iniciais. Todavia, a análise da média do rendimento ao longo do experimento mostra que as colméias instaladas em Franca e Capetinga (esta última pertencente à microrregião de Passos) foram as mais produtivas, seguidas das colméias instaladas em Chave da Taquara (Tabela 1).

$\mathrm{Na}$ Fazenda situada em Franca, além das colméias experimentais instaladas, havia a presença de outras 20 colméias com abelhas Apis mellifera, caracterizando a formação de apiário. Além disso, nesta local também havia um meliponário com abelhas indígenas de diferentes raças. Por estas razões, supõese que o ambiente em Franca já estava adaptado para receber novas abelhas, facilitando a reprodução de abelhas operárias e aumentando à produção de própolis durante o período de amostragem. Na microrregião de Passos, as abelhas adaptaram-se ao meio-ambiente rapidamente, haja vista que o rendimento médio de própolis foi considerado um dos melhores, mesmo não havendo produção de resina em um dos meses em estudo. No decorrer das coletas, notou-se que a vegetação pertencente à Fazenda de Chave da Taquara era rica em pequenos arbustos, mas não havia grande quantidade de plantas fornecedoras de alimento, o que pode justificar a diminuição de produtividade de própolis (Tabela 1). Nas Fazendas situadas em Restinga, Rifaina e Ribeirão Corrente, o rendimento de própolis (Tabela 1) certamente foi influenciado pelo regime de chuvas ao longo do ano. Nas regiões próximas a estes locais, observou-se alto índice pluviométrico com chuvas freqüentes e intensas. As chuvas lavam o néctar presente nas flores, diminuindo a principal fonte de alimento das abelhas. Diante disso, pode ocorrer o enfraquecimento das abelhas em relação à produção de mel e própolis, podendo ocasionar até a perda total da colméia.

\section{Análises das amostras de própolis}

Visando demonstrar de forma clara e objetiva os resultados das análises físico-químicas (Tabela 1), optou-se em apresentar a média de todos os valores encontrados durante o período de amostragem. Nota-se que os coeficientes de variação foram obtidos na faixa de 0,45 a $20,87 \%$, considerando todas as análises. Todavia, conforme Ribani, et al., (2004), métodos que quantificam compostos em macro quantidades requerem $\mathrm{CV}(\%)$ de 1 a $2 \%$ e para métodos de análise de micro quantidades, envolvendo matrizes complexas, são aceitos coeficientes de até $20 \%$. Para a avaliação da qualidade das amostras de própolis, os resultados obtidos foram comparados com os valores preconizados pela norma técnica para fixação de identidade e qualidade da própolis, publicada na portaria do Ministério da Agricultura ${ }^{\circ}$ 574, de 8 de dezembro de 1998 (Brasil, 1998).

Valores de densidade entre 0,900 a $0,915 \mathrm{~g} / \mathrm{mL}$ são aceitáveis, considerando-se que as tinturas foram preparadas utilizando-se solução hidroalcoólica a $70^{\circ}$ GL.

Quanto à determinação do teor de cinzas, a legislação em vigor determina teores máximos de $5 \%$ para a própolis in natura. As amostras de própolis in natura das localidades de Capetinga-MG e de Chave da TaquaraSP apresentaram teores equivalentes a duas vezes o limite estabelecido pela legislação. Coincidentemente, as própolis destas duas localidades apresentaram maiores teores de metabólitos de B. dracunculifolia, conforme dados apresentados na figura 1. Considerando que foram utilizados coletores de madeira, certamente estes componentes inorgânicos estavam presentes nas espécies vegetais visitadas pelas abelhas, principalmente $B$.

Rev. Bras. Farmacogn Braz J. Pharmacogn. 17(1): Jan./Mar. 2007 


\section{dracunculifolia.}

Quanto à determinação da umidade, pode-se considerar que os resultados obtidos foram satisfatórios, pois os teores ficaram abaixo de $8 \%$, o que garante a qualidade da própolis bruta. Os teores de cera, de maneira geral, ficaram abaixo de $25 \%$, o qual corresponde ao valor máximo sugerido para a própolis in natura.

Quanto ao teor de sólidos solúveis, considerando a metodologia utilizada, são aceitáveis valores acima de $7 \%$. Avaliando-se todos os resultados obtidos para a análise do teor de sólidos solúveis percebe-se que as amostras das localidades de Rifaina e Ribeirão Corrente apresentaram teores abaixo dos aceitáveis, em média de 4 e $3 \%$, respectivamente (Tabela 1). Nesta análise, fatores como o tamanho da superfície de contato em relação à própolis in natura, o solvente extrator e o período de extração são determinantes para obtenção de bons resultados. Sabendo-se que o solvente utilizado e o período de extração foram ideais, o tamanho da superfície de contato pode ter influenciado nestes resultados, já que tais amostras de própolis apresentavam-se com características bastante gomosa e maleável, dificultando o processo de pulverização. Todavia, todos os outros valores encontrados para cada local em análise, atenderam as normas em vigor.

Quanto ao teor de flavonóides totais, com relação aos extratos hidroalcoólicos, segundo o Ministério da Agricultura, valores abaixo de $1 \%$ são considerados baixos, valores entre 1 e $2 \%$ são considerados medianos e valores acima de $2 \%$ são considerados elevados. No entanto, valores de no mínimo $0,5 \%$ p/p são aceitáveis para o consumo humano. Pode-se observar, pelos dados apresentados na Tabela 1, que as amostras obtidas das localidades de Franca, Rifaina e Ribeirão Corrente apresentaram baixos teores de flavonóides totais. Os demais locais forneceram amostras de médio e elevado teores de flavonóides totais.

$\mathrm{Na}$ avaliação do índice de oxidação, valores de até 22 segundos indicam atividade antioxidante. Nesta análise, a oxidação natural sofrida pelo agente oxidante durante o período de análise pode influenciar diretamente nos valores obtidos. Neste trabalho, valores de até 60 segundos foram registrados e considerados como limite para obtenção dos dados. Valores acima de 60 segundos não foram considerados, tendo em vista a facilidade de oxidação do permanganato de potássio, o que poderia levar a erro na interpretação final dos resultados.

Os compostos fenólicos (Figura 1) foram quantificados com o uso de padronização interna por meio de cromatografia de fase líquida de alta eficiência. Assim, avaliaram-se somente as localidades de Capetinga, Chave da Taquara, Restinga e Franca, por apresentarem maiores teores de flavonóides totais. Os perfis cromatográficos das amostras dos respectivos locais são apresentados nas Figuras 2, 3, 4, e 5. Nota-se, em geral, que os teores de drupanina, artepelin $\mathrm{C}$ e bacarina ficaram acima de $5 \%$ (Figura 1), considerando as regiões de Capetinga e Chave

88 Rev. Bras. Farmacogn.

Braz J. Pharmacogn.

17(1): Jan./Mar. 2007 da Taquara. Além disso, observou-se que os teores de ácido caféico e ácido cumárico variaram entre 0,5 e 1,5\% para as quatro localidades estudadas. De forma geral, as amostras de Franca se destacaram por apresentar baixos teores dos compostos fenólicos avaliados no período de amostragem.

Nas localidades de Capetinga e Chave da Taquara, as amostras apresentaram coloração verde durante todo período do experimento, bem como teores de flavonóides totais que variaram de 1,8 a $2 \%$ e os resultados das análises de atividade antioxidante ficaram abaixo de 12 segundos. Na avaliação dos principais fenólicos, drupanina, artepelin C e bacarina apresentaram teores médios significativos de 4,9 e $7 \%$, respectivamente (Figura 1). Geralmente, a presença desses componentes juntamente com fragmentos de $B$. dracunculifolia caracteriza a própolis denominada verde. Segundo Akao, et al. (2003), atividades biológicas extremamente importantes, como por exemplo, atividade antitumoral de extratos hidroalcoólicos desse tipo de própolis podem ser atribuídas principalmente à presença destes três ácidos fenólicos. Assim, com base nesse conjunto de resultados pode-se sugerir que os extratos hidroalcoólicos de amostras de própolis destes dois locais poderiam ser utilizados para o consumo humano.

Já as amostras de Restinga apresentaram concentrações médias significativas de drupanina, artepelin $\mathrm{C}$ e bacarina de 3,5 e $10 \%$, respectivamente (Figura 1). No entanto, o teor médio de flavonóides totais para esta localidade foi de $0,7 \% \mathrm{p} / \mathrm{p}$. A atividade antioxidante ficou em torno de 40 segundos e o teor de cera, apesar de atender as normas em vigor, foi relativamente elevado, em média de $20 \%$. Amostras de própolis que apresentam teores de ceras entre 20 a $25 \%$ são bastante resinosas, dificultando seu manejo na obtenção dos extratos hidroalcoólicos, o que pode influenciar nos resultados das análises desses extratos. Todavia, considerando os teores de ácidos fenólicos e flavonóides totais, estes extratos também poderiam ser utilizados para o consumo humano. Importante ressaltar que apesar dessas amostras apresentarem teores de fenólicos aceitáveis, as mesmas não foram consideradas de cor verde, pois devido aos altos teores de ceras, a eventual presença de fragmentos de alecrim do campo não foi visualizada, prevalecendo assim, coloração marrom ao longo do período de amostragem.

Os resultados deste trabalho permitem inferir que em todas as localidades estudadas houve produção de própolis e que a própolis verde foi produzida principalmente em localidades onde a mata nativa, característica de cerrado, era predominante. Nas demais áreas onde havia a interferência mais acentuada da atividade agrícola, com culturas de cana-de-açúcar, café e eucaliptos, a própolis produzida não poderia ser caracterizada como própolis verde. Portanto, para se produzir própolis verde, a qual tem maior valor comercial, há que se preservarem os ecossistemas do cerrado. 
$\square$ Capetinga-MG $\square$ Chave da Taquara-SP $\square$ Restinga-SP $\square$ Franca-SP

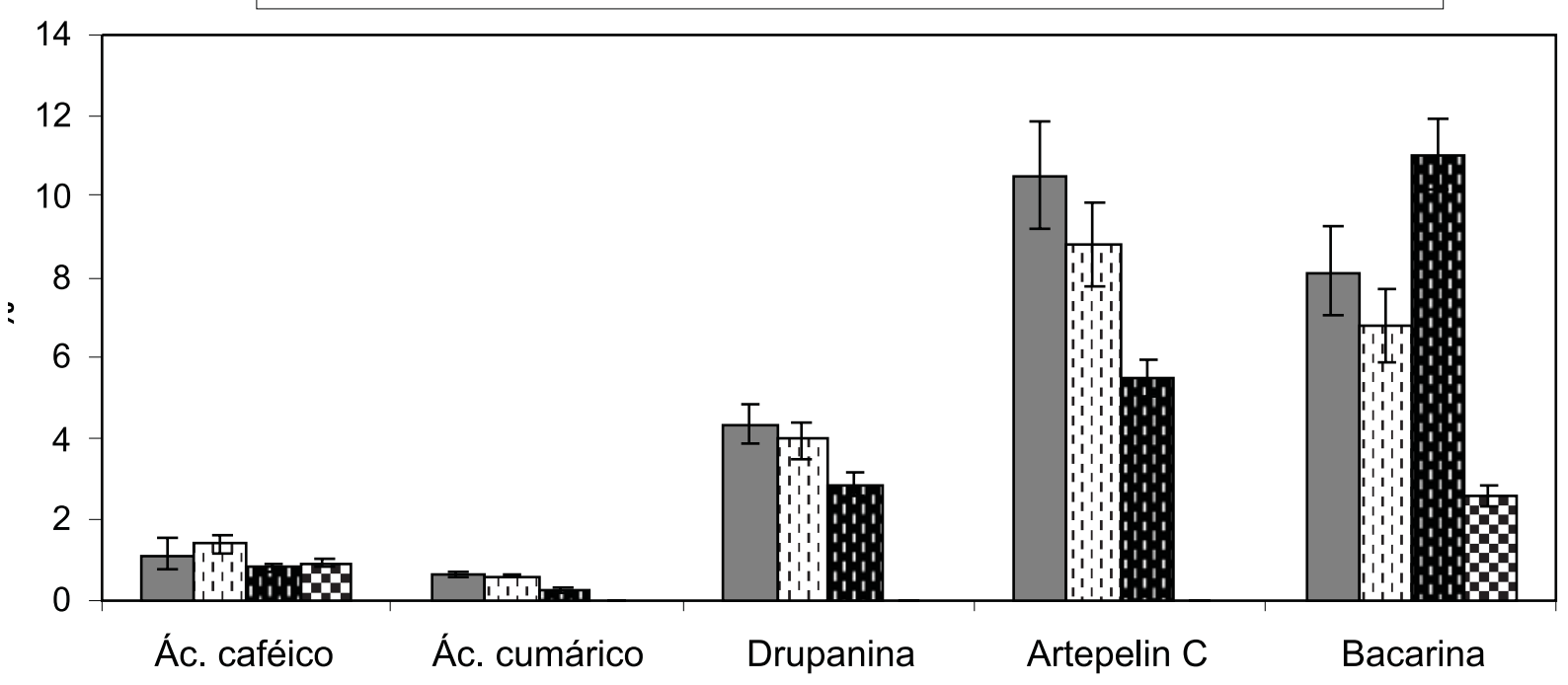

Figura 1. Média dos teores dos principais ácidos fenólicos presentes nas quatro melhores amostras estudadas.

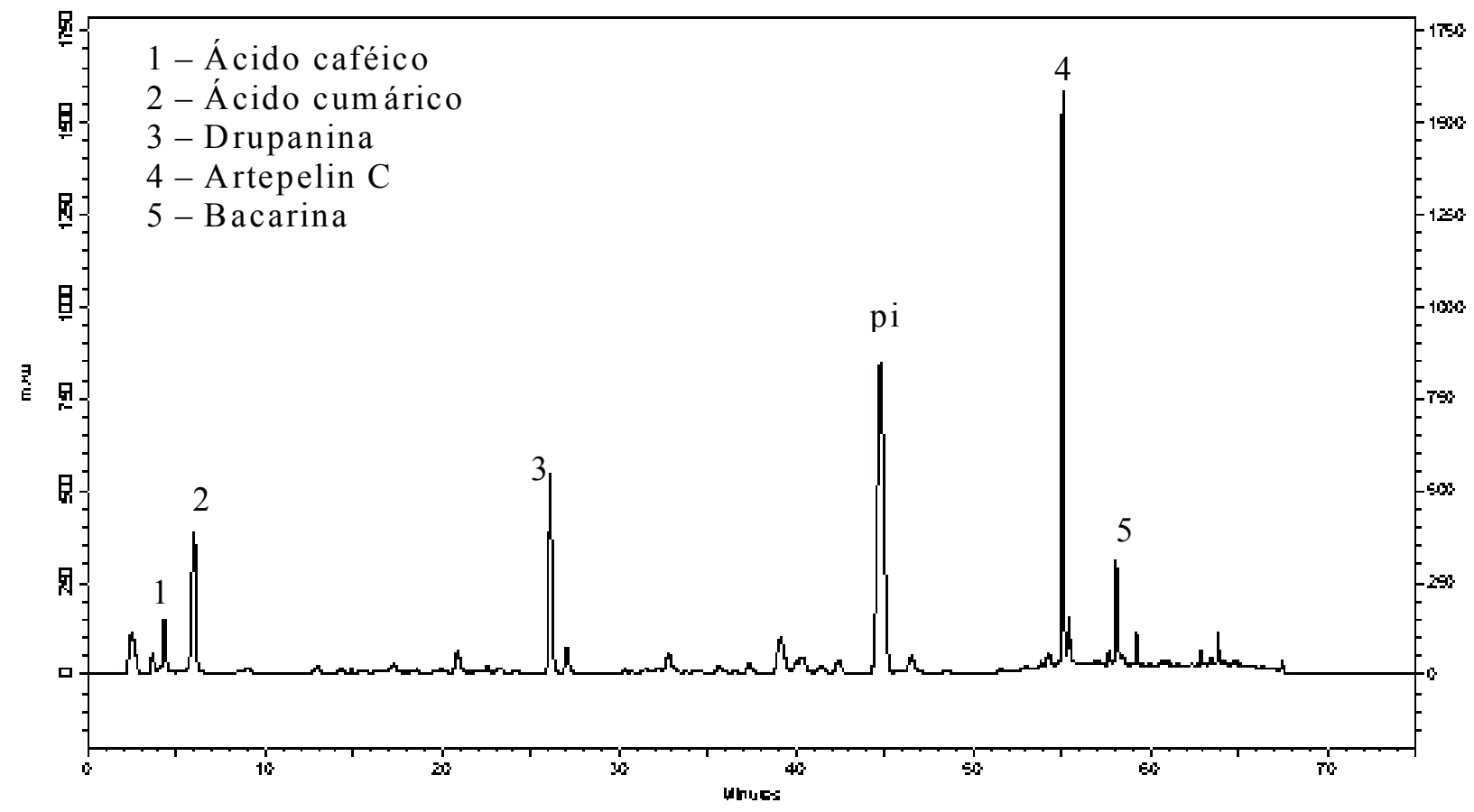

Figura 2. Cromatograma obtido em CLAE, $280 \mathrm{~nm}$, da amostra proveniente de Capetinga. 


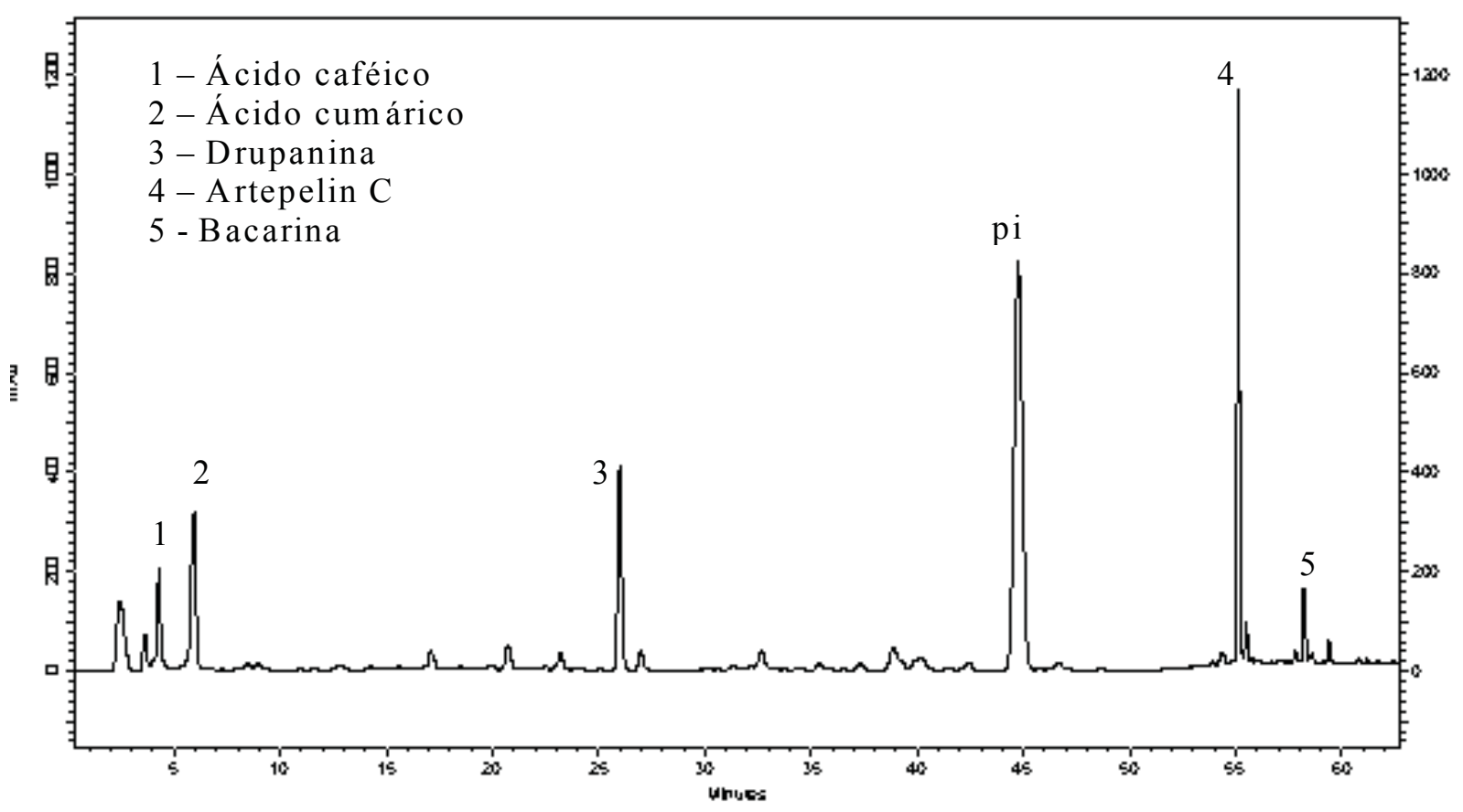

Figura 3. Cromatograma obtido em CLAE, $280 \mathrm{~nm}$, da amostra proveniente de Chave da Taquara.

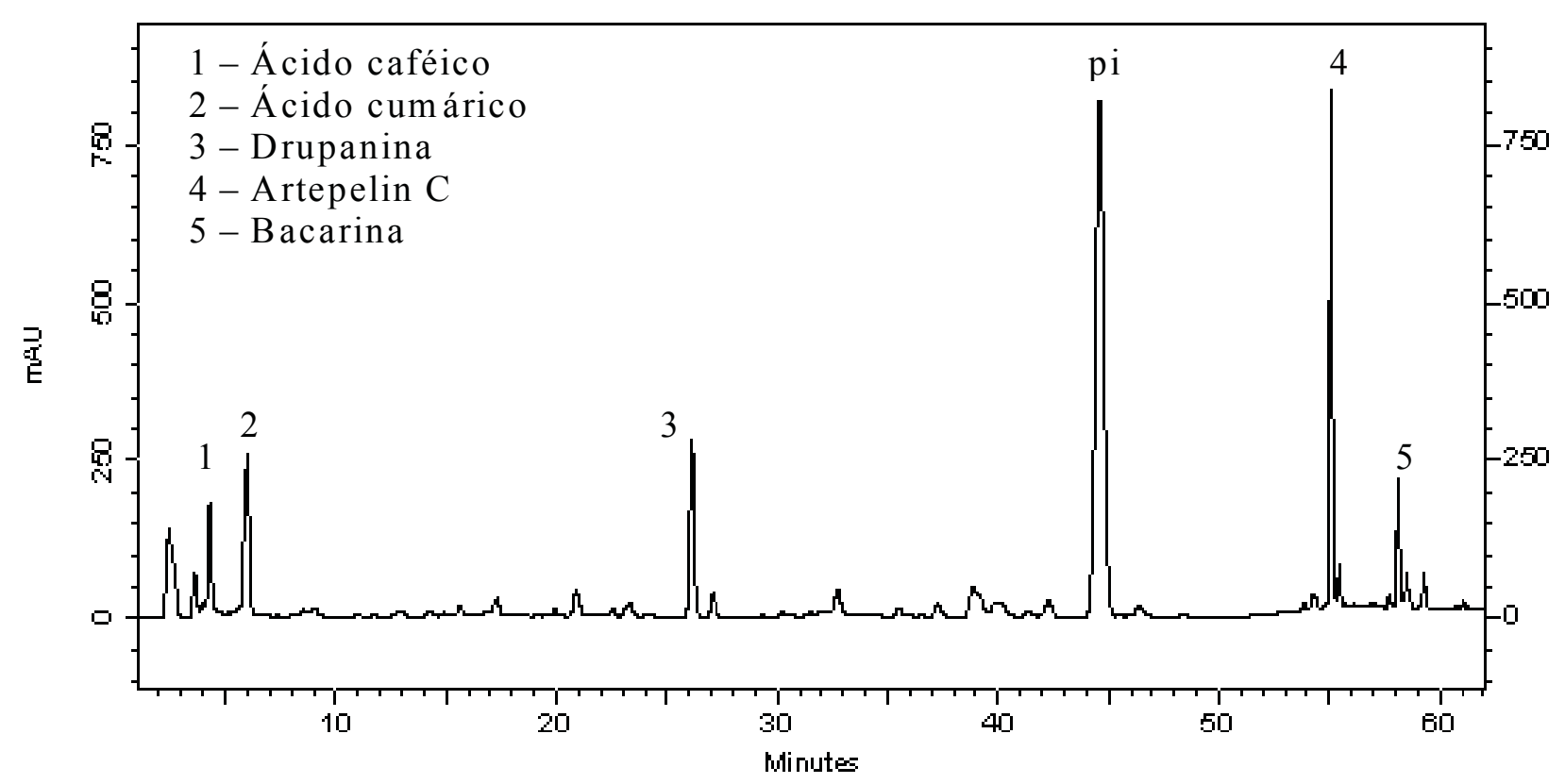

Figura 4. Cromatograma obtido em CLAE, $280 \mathrm{~nm}$, da amostra proveniente de Restinga. 


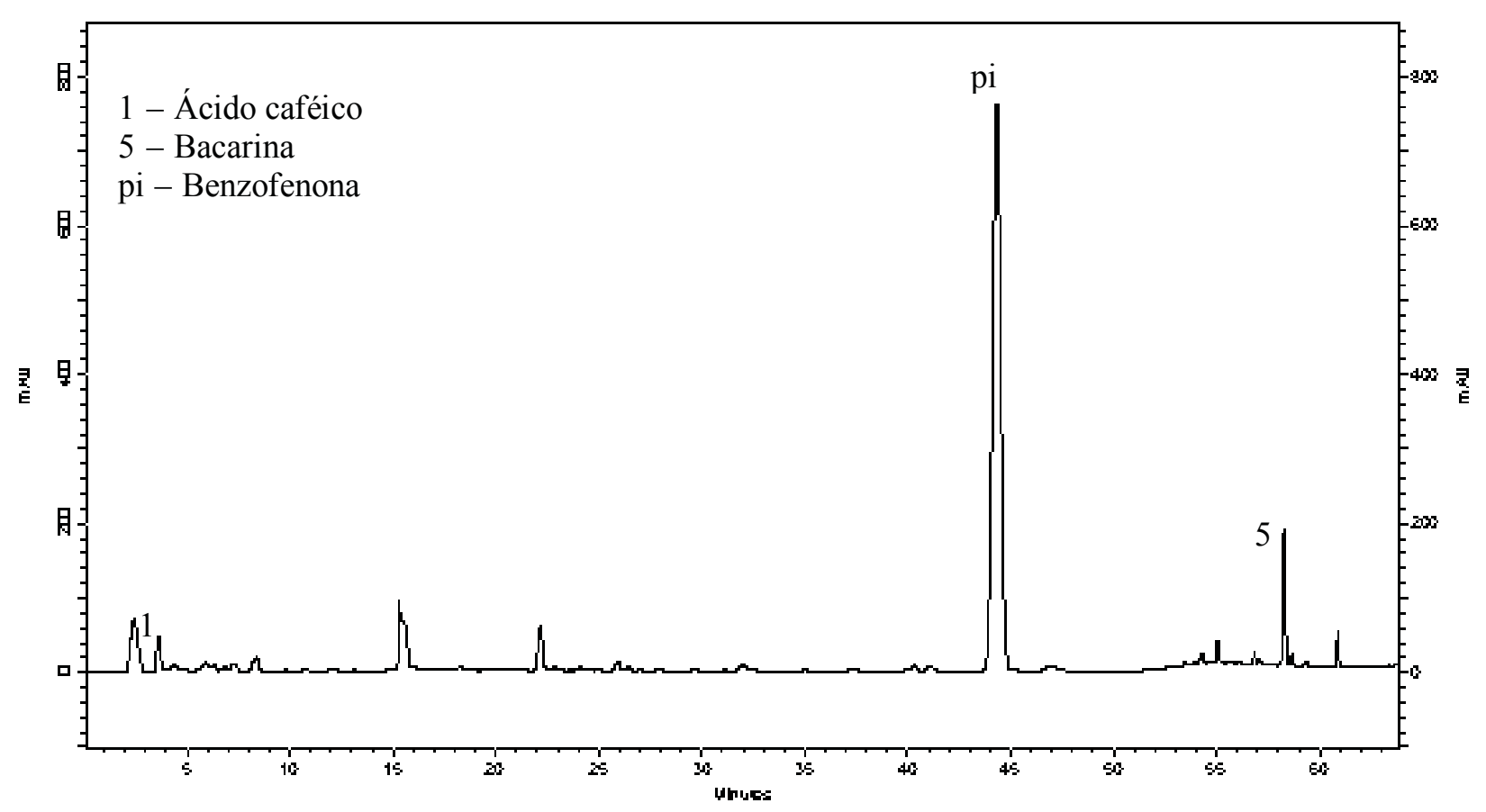

Figura 5. Cromatograma obtido em CLAE, $280 \mathrm{~nm}$, da amostra proveniente de Franca.

\section{CONCLUSÃO}

Os resultados apresentados demonstram a importância das análises realizadas para determinação da qualidade de diferentes amostras de própolis. Existe uma estreita relação entre Apis mellifera e B. dracunculifolia na produção de própolis verde. Contudo, em havendo a presença de B. dracunculifolia, A. mellifera produz, preferencialmente, própolis verde, independentemente da época do ano ou do estágio de crescimento da planta, conforme observado no presente trabalho, considerando o período de amostragem nas localidades de Capetinga-MG e Chave da Taquara-SP. Para produção de própolis verde, as áreas de cerrado, nas quais ocorre $B$. dracunculifolia nativa, devem ser preservadas para garantir a produção de própolis de alto valor comercial.

\section{AGRADECIMENTOS}

Os autores agradecem a Universidade de Franca pelo apoio logístico e financeiro para desenvolvimento do projeto, bem como aos proprietários das Fazendas onde foram realizados os experimentos. João Paulo Barreto de Sousa agradece ao CNPQ pela bolsa de Iniciação Científica concedida.

\section{REFERÊNCIAS}

Akao Y, Maruyama H, Matsumoto K, Ohguchi K, Nishizawa K, Sakamoto T, Araki Y, Mishima S, Nozawa Y 2003. Cell growth inhibitory effect of cinnamic acid derivatives from propolis on human tumor cell lines.
Biol Pharm Bull 26: 1057-1059.

Bankova VS, Popov SS, Marekov NL 1998. On the chemical composition of some propolis fractions with antiviral action. Acta Microbiol Bulg 23: 52-57.

Bankova VS, Marcucci MC 1999. Phytochemical evidence for the plant origin of Brazilian propolis from São Paulo State. Z Natuforsch C 54: 401-405.

Bankova VS, Castro SL, Marcucci MC 2000. Propolis: recent advances in chemistry and plant origin. Apidologie 31: $3-15$.

Bankova VS 2005. Recent trends and important developments in propolis research. Evid Based Complement Alternat Med 2: 29-32.

Barros MP, Sousa JPB, Bastos JK, Andrade SF 2006. Effect of Brazilian green propolis on experimental gastric ulcers in rats. $J$ Ethnopharmacol, DOI:10.1016/j.jep.

Bazo AP, Rodrigues MAM, Sforcin JM, Viana de Camargo JL, Ribeiro LR, Salvadori DMF 2002. Protective action of propolis on the rat colon carcinogenesis. Teratogen Carcinogen Mutagen 22: 183-194.

Brasil 1998. Ministério da Agricultura e do Abastecimento. Art. 83, inciso IV do Regimento Interno da Secretaria, aprovado pela Portaria Ministerial $\mathrm{n}^{\circ} 574$, de 8 de dezembro de 1998. Disponível em: http://www. apacame.org.br/mensagemdoce/60/normas.htm acessado em março de 2006.

Da Silva Filho AA 2006. Estudo fitoquímico, de cultivo e das atividades biológicas de Baccharis dracunculifolia D.C. (Asteraceae), a principal fonte botânica da própolis verde. Ribeirão Preto-SP, 188 p. Tese de Doutorado - Programa de Pós-Graduação em Ciências Farmacêuticas, Universidade de São Paulo.

Farmacopéia Brasileira 1977. 4 ${ }^{\mathrm{a}}$ Edição, p. 988 (Método Modificado).

Gregório LE 2003. Influência da sazonalidade na composição 
polínica, no perfil químico e na atividade antimicrobiana da própolis produzida em CajurúSP. Ribeirão Preto-SP, 174 p. Dissertação de Mestrado - Programa de Pós-Graduação em Ciências Farmacêuticas, Universidade de São Paulo.

Marcucci MC, Ferreres F, Garcia-Viguera C, Bankova V, De Castro SL, Dantas AP, Valente PH, Paulino N 2001. Phenolics compounds from Brazilian propolis with pharmacological activities. J Ethnopharmacol 74: 105-112.

Missima F, Da Silva Filho AA, Nunes GA, Bueno PCP, Sousa JPB, Bastos JK, Sforcin JM 2006. Effect of Baccharis dracunculifolia D.C. (Asteraceae) extracts and its isolated compounds on macrophage activation. $J$. Pharm Pharmacol Manuscrito No JPP-D-06-00167R1 (In Press).

Murad JM, Calvi SA, Soares AMVC, Bankova VS, Sforcin JM 2002. Effects of propolis from Brazil and Bulgaria on fungicidal activity of macrophages against Paracoccidioides brasiliensis. J Ethnopharmacol 79: 331-334.

Park YK, Alencar SM, Aguiar CL 2002. Botanical origin and chemical composition of Brazilian propolis. J Agric Food Chem 50: 2502-2506.

Park YK, Paredes-Guzman JF, Aguiar CL, Alencar SM, Fujiwara FY 2004. Chemical constituents in Baccharis dracunculifolia as the main botanical origin of southeastern Brazilian propolis. J Agric Food Chem 52: 1100-1103.

Pereira AS, Seixas FRMS, Aquino Neto FR 2002. Própolis: 100 anos de pesquisas e suas perspectivas futuras. Quim Nova 25: 321-326.

Reis CMF, Carvalho JCT, Caputo LRG, Patrício KCM, Barbosa MVJ, Chieff AL, Bastos JK 2000. Atividade antiinflamatória, antiúlcera gástrica e toxicidade subcrôncia do extrato etanólico de própolis. Rev Bras Farmacogn 10: 43-52.

Ribani M, Bottoli CBG, Collins CH, Jardim ICSF, Melo LFC 2004. Validação em métodos cromatográficos e eletroforéticos. Quim Nova 27: 771-780

Salatino A 2005. Origin and chemical variation of brasilian propolis. Evid Based Complement Alternat Med 2: 33-38.

Santos FA, Bastos EMAF, Maia ABRA, Uzeda M, Carvalho MAR, Farias LM, Moreira ESA 2003. Brazilian propolis: Physicochemical properties, plant origin and antibacterial activity on periodontopathogens. Phytother Res 17: 285-289.

Sforcin JM, Fernandes Jr A, Lopes CAM, Bankova V, Funari SRC 2000. Seasonal effect on Brazilian propolis antibacterial activity. J Ethnopharmacol 73: 243-249.

Sforcin JM, Orsi RO, Bankova V 2005. Effect of propolis, some isolated compounds and its source plant on antibody production. J Ethnopharmacol 98: 301-305.

Simões LMC, Gregorio LE, Da Silva Filho AA, De Souza ML, Azzolini AECS, Bastos JK, Lucisano-Valim YM 2004. Effect of Brazilian green propolis on the production of reactive oxygen species by stimulated neutrophils. $J$ Ethnopharmacol 94: 59-65.

Soares AKA, Carmo GC, Quental DP, Nascimento DF, Bezerra FAF, Moraes MO, Moraes MEA 2006. Avaliação da segurança clínica de um fitoterápico contendo Mikania glomerata, Grindelia robusta, Copaifera officinalis,
Myroxylon toluifera, Nasturtium officinale, própolis e mel em voluntários saudáveis. Rev Bras Farmacogn 16: 447-454.

Tavares JP, Martins IL, Vieira AS, Lima FAV, Bezerra FAF, Moraes MO, Moraes MEA2006. Estudo de toxicologia clínica de um fitoterápico a base de associações de plantas, mel e própolis. Rev Bras Farmacogn 16: 350356.

Woisky RG 1996. Métodos de controle químico de amostras de própolis. São Paulo, 74p. Dissertação de Mestrado - Faculdade de Ciências Farmacêuticas de São Paulo, Universidade de São Paulo. 